Cad.Est.Ling., Campinas, (45):43-48, Jul./Dez. 2003

\title{
O COGITO REVISITADO
}

\author{
NINA VIRGÍNIA DE ARAÚJO LEITE \\ (UNICAMP)
}

\begin{abstract}
The present paper aims at discussing the questions related to Linguistics and Cognition from the psychoanalytical perspective, focusing on the notion of a subject of modern science. The strategy for doing this centres on re-visiting the cartesian cogito and demonstrating the linguistic nature of the subjective experience implied in the inauguration of the so called modern science. It demonstrates how the freudian discoveries can be taken as necessary to build a notion of subjectivity compatible to the scientific status of Linguistics.
\end{abstract}

O tema da presente conferência - Lingüística e Cognição - convoca questões de importância crucial para uma abordagem da epistemologia da lingüística e, por extensão, da ciência moderna, levantando de imediato o problema - sempre presente - da relação da ciência da linguagem com outras disciplinas científicas, uma vez que cada ciência inaugura uma nova ordem de discursividade. Uma das consequiências de tal proposta é a oportunidade para discutirmos, para além dos temas específicos que se inscrevem dentro de um programa cognitivista de pesquisas sobre a linguagem, as diferentes formas em que se presentifica a contradição - entre o objeto real e o objeto de conhecimento - constitutiva de uma ciência e as articulações possíveis que se abrem com outros campos do saber atual. Mais ainda, tratando-se da ciência que toma a língua como objeto, impõe-se uma reflexão quanto aos limites que incidem sobre o próprio conhecimento que a ciência produz. Pois, independente da forma como definimos o empreendimento científico e o lugar específico que a lingüística aí ocupa, trata-se da produção de conhecimento, isto é, da cognição e da linguagem. O que se afirma aqui é a necessidade de reconhecimento do caráter de construto simbólico da ciência e a sua conseqüente subordinação às leis do registro simbólico. É dentro dessa perspectiva, e com o objetivo de mobilizar questões da articulação da ciência lingüística com outros campos, especificamente com a psicanálise - a qual circunscreve um tipo de relação bastante singular com a linguagem - que pretendo revisitar o COGITO cartesiano.

O surgimento da ciência lingüística atesta o reconhecimento à linguagem de uma realidade autônoma e independente tanto do psicológico quanto do social, rompendo com a circularidade do campo da complementaridade que, segundo P. Henry (1992) pode ser assim enunciado: do humano, tudo aquilo que não é da ordem do psicológico, é social e reciprocamente (p.114). Como indica o autor, sob o domínio da problemática da complementaridade não há lugar para o conceito de língua e para uma ordem de realidade autônoma correspondente. É, pois, rompendo com tal problemática (lembremos as dificuldades de Saussure para cernir o que é da língua utilizando-se das categorias de social e de psíquico), que a ciência da linguagem isola um espaço que não deixa, entretanto, e por essa razão, de estar constantemente ameaçado de ser novamente recoberto por um dos pólos: o psicológico ou o social. 
Um dos pontos que atualiza a iminente ligação com o campo da complementaridade, ameaçando assim desfazer a autonomia do objeto língua, é a concepção de "sujeito da ciência" tomada de empréstimo deste campo. Podemos afirmar que a identificação entre indivíduo (enquanto objeto natural) e sujeito, fundamentando uma concepção teórica de subjetividade natural, ao mesmo tempo individual e universal, característica do campo da complementaridade, constitui o fundamento da onipresente ameaça de redução do lingüístico quer ao psicológico, ao social ou ao biológico. Não é por outra razão que encontramos afirmações como a de P. Henry (1992): O lugar atribuído ao sujeito nas teorias lingüísticas comanda a posição tomada com relação ao sentido, naquilo que se entende por língua; ele determina a concepção global de gramática e, para além, o tipo de prova assim como os resultados (p.113).

A partir destas breves considerações é possível concluir que, enquanto o "sujeito da ciência" ou "sujeito do conhecimento" estiver identificado com o indivíduo-sujeito, a ciência da língua estará irremediavelmente presa ou ameaçada de ser capturada na problemática de onde se desligou para se constituir. A questão, então, se impõe quanto ao lugar teórico que pode realizar uma subversão do sujeito do campo da complementaridade. É aqui que encontramos a psicanálise e o materialismo histórico.

Tratarei de apresentar, através de uma leitura do Cogito cartesiano, de que forma a psicanálise pode estar incluída na discussão das questões pertinentes à ciência da linguagem, especialmente quando são tematizadas as relações entre esta ciência e a cognição. Adianto que é apenas porque a psicanálise não pode prescindir da dimensão da linguagem para a definição ou determinação de seu objeto - o inconsciente - que as elaborações realizadas em seu campo podem ter alguma importância (ou pertinência) para a discussão levantada. Afinal, tanto a psicanálise quanto a lingüística e o materialismo histórico tem suas práticas científicas próprias marcadas pela referência às noções de sujeito e de linguagem. Sendo assim, como afirma P. Henry (1992), ...o que cada uma dessas posições científicas pode demonstrar, no que diz respeito ao real que se mostra, através dessas noções, na sua historicidade e sua materialidade, não poderia ser indiferente às outras. Disso depende que a questão lingüística seja formulada fora da referência ao campo da complementaridade (p.148)

Identificamos, nessa citação, a indicação clara de uma relação necessária da lingüística com a noção de subjetividade colocada em jogo pela psicanálise e pelo materialismo histórico, a fim de que a autonomia do lingüístico possa ser mantida. Longe de substituir a referência ao psicológico, restituindo o campo da complementaridade, a psicanálise cumpriria, nessa proposta, o lugar de reenviar a ciência da linguagem a seu campo próprio. Isto porque permite pensar um outro estatuto para o sujeito da ciência, inteiramente determinado pela sua relação com a linguagem, em total disjunção com relação ao sujeito da psicologia.

\section{II}

Sabe-se, a partir de Lacan, que o sujeito sobre o qual a prática psicanalítica opera é o sujeito da ciência. Tal afirmação, embora surpreendente e aparentemente paradoxal, ilumina a natureza do sujeito implicado na descoberta freudiana do inconsciente. Com isso se afirma que a constituição histórica do sujeito da ciência, entendida aqui como ciência moderna, é a condição da subversão realizada por Freud na concepção de subjetividade. Ou seja, afirmamos que a ciência é essencial à existência da psicanálise. Observo que são muitas as referências de Lacan ao "sujeito da civilização científica" indicando que seria esse sujeito - à exclusão de qualquer outro - aquele que interessa à psicanálise. A ciência, aqui referida, remete portanto àquela na qual estamos presos, a ciência que forma o contexto de ação de todos nós, no tempo em que vivemos; contexto do qual não pode escapar o próprio psicanalista, uma vez que ela faz parte de suas condições. 
Mas, tratando-se da ciência moderna, que noção de sujeito está aqui subsumida? Para Lacan, há nesse contexto, uma única referência: o sujeito da ciência moderna é instituído no procedimento cartesiano, mais especificamente no momento do Cogito. Portanto, o tratamento da hipótese do sujeito da ciência passa por Descartes. Lacan reconhece em Descartes a ruptura com a tradição filosófica de um sujeito que tem consistência a priori, na medida em que propõe um sujeito que ganha seu estatuto de ser no ato de pensar, de ou por cogitar. Para Descartes, apenas a razão pode determinar a certeza, não os sentidos ou a imaginação.

Muitas foram as oportunidades em que Lacan abordou o Cogito cartesiano; nos Escritos (1966) encontramos principalmente dois textos fundamentais: "A instância da letra no inconsciente ou a razão desde Freud" e "A ciência e a verdade", além das inúmeras referências em diversos seminários, durante todo o percurso de seu ensino. Podemos afirmar que Lacan analisou sem cessar o Cogito cartesiano, a cada vez de forma diferente, retirando diversas conseqüências para o avanço de suas teses. No entanto, é necessário indicar que a revisão do fundamento do sujeito cartesiano se anuncia em Freud quando da própria descoberta do inconsciente através do estudo dos sintomas, dos sonhos, dos atos falhos, dos chistes - as chamadas formações do inconsciente - em que se verifica a presença de um pensamento que não pode ser creditado ao domínio da consciência ou, dito de outro modo, um pensamento que não é sustentado pela cogitação de um Eu.

\section{III}

No capítulo VII de A Interpretação de Sonhos (1900), intitulado a "Psicologia dos processos oníricos", encontramos na primeira parte (O esquecimento dos sonhos), o tratamento que Freud dá ao que se presentifica, no curso do relato do sonho, como dúvida, incerteza ou falha de memória; observamos, nesse texto, o estatuto por ele atribuído aos detalhes que parecem ínfimos, sem conexão aparente com os outros elementos mais destacados do sonho. Podemos verificar a mesma importância atribuída ao que parece ser indiferente ou trivial, importante ou destacado no relato. Aquilo mesmo que se apresenta como duvidoso, falha de expressão ou incorreção é incluído no texto do sonho como signo de um pensamento no conteúdo latente. Freud afirma: Em resumo, tratamos como a um texto sagrado o que na opinião de outros autores não seria senão uma improvisação arbitrária... (p.508). Concorda, portanto, que realizamos desfigurações no sonho na tentativa de reproduzi-lo, mas reconhece aí o processo de elaboração secundária do sonho por parte da instância do pensamento normal (vale dizer, consciente), o qual freqüentemente incorre em um mal entendido sobre aquele. Associa tal desfiguração com o processo da elaboração a que são submetidos regularmente os pensamentos oníricos em conseqüência da censura do sonho. Contraria, deste modo, a opinião de outros autores que, julgando arbitrárias as modificações do sonho no relato que dele fica e em sua versão em palavras, não crêem poder chegar ao conhecimento do sonho. Para tais autores, o fato de o juízo ou o pensamento consciente não poderem atribuir certeza ao relato invalida as tentativas de conhecimento. Freud julga que tais autores subestimam o determinismo dentro do psíquico e afirma: não há nada aí de arbitrário (p.509). Cita um exemplo: pretendo que me ocorra um número ao acaso, mas isto não é possível, pois o número que me ocorre está comandado de maneira necessária por pensamentos que há em mim, ainda que estejam distantes de meu desígnio do momento. Do mesmo modo, podemos afirmar que as alterações às quais submetemos o sonho na redação de vigília tampouco são arbitrárias. Elas mantém um laço associativo com o conteúdo em cujo lugar se colocam e nos servem para indicar-nos o caminho para esse conteúdo, o qual por sua vez, pode ser o substituto de outro (p.509).

O que é importante de ser notado é que Freud mantém a necessidade da busca da certeza incluindo ou, até mesmo, a partir daquilo que opõe resistência à consciência. Há pensamentos em mim : embora não possa sustentar os pensamentos a partir de uma instância do Eu, há pensamentos; para a psicanálise, o pensamento começa no inconsciente, este lugar Outro de onde sou pensado. 
No que respeita especificamente ao tratamento da dúvida que o relato do sonho suscita em nosso juízo, Freud afirma que, embora ela careça de uma justificação intelectual, ela não está destituída de significação: é como signo da censura onírica, da resistência à irrupção dos pensamentos oníricos na consciência que a dúvida adquire inteligibilidade. Ela é incorporada no texto do sonho. Como afirma Lacan (1979)

Freud nos convida a integrar ao texto do sonho o que chamarei o colofão da dúvida - o colofão, num texto antigo, é aquela mãozinha indicativa que se imprimia na margem, no tempo em que ainda se tinha tipografia. $\mathrm{O}$ colofão da dúvida faz parte do texto. Isto nos mostra que Freud coloca sua certeza, Gewissheit, somente na constelação dos significantes, tal como eles resultam da narrativa, do comentário, da associação pouco importando a retratação (p.47).

Podemos, então, dizer que na experiência do inconsciente trata-se de pensamentos e afirmar, com Lacan, que Freud é cartesiano, porque é na dúvida, no momento em que o analisante põe dúvida sobre o seu relato que ele, Freud, adquire a certeza de que ali existe um pensamento inconsciente a ser descoberto. Em Descartes, é no exercício da dúvida que o sujeito adquire uma certeza: a certeza de ser um sujeito pensante. Então, há uma identidade no encaminhamento de Descartes e Freud, mas há também uma dissimetria fundamental. Pois o sujeito que em Descartes vem a adquirir uma substância - uma substância pensante - não tem esse estatuto na psicanálise, uma vez que atuando enquanto ausente, tal pensamento não pode servir para identificar o sujeito, não responde pelo seu ser.

\section{IV}

A tese de que o sujeito da ciência moderna é o sujeito do Cogito cartesiano implica considerar, como afirma Milner (1996) que o pensamento da ciência precisa daquilo de que o Cogito é testemunho. O fato de que o autor das Meditações seja também o criador da geometria analítica e o autor de uma Dióptrica constitui, por certo, uma prova de peso (p.33).

Milner observa que não se trata, nesse caso, de uma simples contingência histórica mas, sim, de um parentesco discursivo e apresenta a seguinte argumentação: a física matematizada elimina todas as qualidades dos existentes e, portanto, uma teoria do sujeito que pretenda responder a tal física deverá também despojá-lo de toda qualidade. Este sujeito, constituído de acordo com a determinação típica da ciência é o sujeito da ciência. Segundo Milner (1996) a este sujeito:

...não lhe convirão as marcas qualitativas da individualidade empírica, seja ela psíquica ou somática; tampouco lhe convirão as propriedades qualitativas de uma alma; ele não é mortal nem imortal, puro nem impuro, justo nem injusto, pecador nem santo, condenado nem salvo; não lhe convirão nem mesmo as propriedades formais que durante muito tempo havíamos imaginado constitutivas da subjetividade como tal; ele não tem SI, nem reflexividade, nem consciência (p.33).

É justamente este existente que emerge do Cogito cartesiano. É a esse existente - correlato sem qualidade suposto num pensamento sem qualidade - que Lacan vai chamar de sujeito da ciência moderna (não é Descartes quem o nomeia desse modo, mas Lacan). Ocorre que Descartes não se deteve neste ponto e acabou passando para a afirmação da consciência e para o pensamento qualificado (Lacan se refere a uma passagem ao ato de Descartes); tal passagem fica evidenciada na fórmula "Penso, logo sou" onde se inscreve uma báscula do pensamento ao ser; é por isto que Lacan destaca apenas o primeiro tempo do encaminhamento cartesiano e enfatiza a dimensão sem propriedade do pensamento compatível com a ciência moderna e a psicanálise. Pois, se existe 
pensamento no sonho - e nas outras formações do inconsciente - então, o pensamento não é um corolário da consciência de si.

Assim, Descartes - o primeiro filósofo moderno - inaugura uma nova racionalidade científica, realizando um corte na relação do sujeito com o saber, uma ruptura com a episteme antiga. Portanto, é possível afirmar, como Lacan inúmeras vezes faz, que Descartes inventa o sujeito da ciência e, mais ainda, que o sujeito freudiano não é outro que o sujeito cartesiano, (afirmação que trataremos de demonstrar). Como afirma na primeira aula do seminário XVII [O avesso da psicanálise]:

Foi só no dia em que, num movimento de renúncia a esse saber [o saber do escravo transmutado em saber teórico], por assim dizer, mal adquirido, alguém pela primeira vez extraiu da relação estrita entre S1 e S2 a função do sujeito como tal, eu nomeei Descartes - ....foi nesse dia que a ciência nasceu (p.20)

É porque introduziu o sujeito na ciência antiga que Descartes a converteu em ciência moderna. Mas é preciso não esquecer que a ciência antiga tinha já realizado uma ruptura com relação a uma outra forma de saber, aquela do mythos, sustentada no exercício da palavra, substituindo-a pelo logos, enquanto discurso articulado. Como afirmado por Porge (2000), no mito, a verdade é imanente ao fato de contar, não havendo distinção entre a palavra e a coisa (poderíamos dizer entre o saber e a verdade). Já no logos, um saber pode se afirmar pela coerência interna do discurso. De fato, com Platão, trata-se de um saber que é transparente a si mesmo, um saber do ser que é eterno e necessário, situado no mundo das Idéias; a verdade seria adequada ao saber, não havendo, então, divisão entre o saber e a verdade. Tal divisão será inaugurada pela operação do Cogito cartesiano. É porque o domínio da verdade terá que ficar a cargo de um Deus que não seja enganador que se abre a possibilidade de produção de um saber, isto é, da ciência. Marco aqui a palavra "produção", uma vez que ela inscreve a diferença para com a forma de saber anterior que se baseava na transformação, pelo mestre antigo, do saber extraído do escravo. Portanto, podemos dizer que a divisão entre o saber e a verdade é correlata da própria possibilidade da ciência. Que na seqüência tenha ocorrido um fechamento (poderíamos dizer um apagamento) desta divisão inaugural, em nada deprecia a importância da divisão entre saber e verdade como fundante da ciência. O gesto de Freud se encarregará de reabrir a divisão entre o saber e a verdade, uma vez que vai interrogar o saber no lugar da verdade ou, dito de outro modo, vai dar estatuto de verdade ao saber articulado pelo sujeito que fala.

Para analisar o Cogito cartesiano, como vimos, Lacan não se detém na abordagem da fórmula conhecida "Penso, logo sou" como enunciado no qual culmina o procedimento de Descartes. Ele critica o modo como o discurso comum se apropriou dessa fórmula e denuncia os esforços que os filósofos fizeram para restituir o sujeito do Cogito ao lugar anteriormente ocupado pelo sujeito na tradição filosófica. O que ele vai relevar no Cogito é o processo de sua enunciação, esforçando-se para suspender a passagem do primeiro para o segundo momento, ou seja, a passagem do exercício da dúvida metódica para a afirmação da fórmula. Ele concentra sua atenção sobre o momento, relativamente pontual, do surgimento do sujeito cartesiano no curso da Segunda Meditação, desprezando as tentativas ulteriores de Descartes de dar novamente a esse sujeito qualidades e substância. No curso de suas elaborações, Lacan irá sempre privilegiar esse momento evanescente do sujeito, quando Descartes inaugura o conceito de uma certeza que se sustentaria unicamente no Eu penso da cogitação.

Há, então, uma identidade do encaminhamento de Freud e de Descartes, na medida em que é o sujeito da certeza o que visavam. Assim, Lacan (1973) afirma que o encaminhamento de Freud é cartesiano - no sentido de que parte do fundamento do sujeito da certeza (p.38). Lá onde duvida, 
Freud tem certeza de que um pensamento está lá, enquanto pensamento inconsciente, ou seja, revelando-se como ausente para a consciência. É a este lugar de ausência, diz Lacan, que Freud chama o eu penso pelo qual vai se revelar o sujeito; este pensamento, enquanto inconsciente, está disjunto do eu sou. Daí podermos afirmar a dissimetria radical entre o Eu e o Sujeito. O fato de existir pensamento sem Eu, sem consciência de Si não implica não haver sujeito; se existe pensar, há sujeito: ISSO pensa. Assim, a experiência freudiana demonstra que nem o sujeito nem o pensamento exigem a consciência.

Tratando o Cogito cartesiano como uma experiência de fala, com suas ambigüidades e equívocos, Lacan observa que o "eu penso" não é um pensamento (o "eu penso" não pode ser destacado do fato de que só é formulado pelo dizer) e sim um ato de fala, distinguindo então o Eu do enunciado "eu penso" e o Eu da enunciação. Com efeito, o eu que enuncia, eu da enunciação, não é o eu do enunciado, quer dizer, o shifter que, no enunciado, o designa (p.133). É por não distinguir esses dois planos que o pensamento pode introduzir absurdos e chegar a ver uma antinomia da razão no enunciado eu minto. Vemos que tudo se organiza em uma dialética em que $[e u]$ do enunciado é distinto de eu da enunciação. No plano do enunciado temos o "eu penso" e no plano da enunciação Cogito, vale dizer: ISSO pensa.

O tema do Cogito cartesiano preserva sua força por estar sempre sendo infletido. É difícil apreender na plenitude de sua potência esse penso, logo existo; talvez ele não passe, como diz Lacan, de uma tirada espirituosa.

O que importa destacar, para finalizar, é que quando se dá primazia à cadeia significante para se pensar o estatuto do sujeito, então a subjetividade não poderá mais estar referida ao indivíduo; o sujeito não é sua inteligência; o sujeito está descentrado com relação ao indivíduo. O sujeito como tal, funcionando como sujeito que fala, é algo diferente de um organismo que se adapta. Todo o pensamento freudiano demonstra isso: a heterogeneidade da função significante, o caráter radical da relação do sujeito ao Outro, na medida em que ele fala. Há um sujeito que pensa e exatamente de acordo com a leis da organização significante. É a esse significante em ação que se dá o nome de inconsciente.

\section{$\overline{\text { REFERÊNCIAS BIBLIOGRÁFICAS }}$}

FREUD, S. (1969). A interpretação de Sonhos (1900), Obras Psicológicas Completas de Sigmund Freud, vol. IV, trad. de Walderedo Ismael de Oliveira, Rio de Janeiro: Imago.

HENRY, P. (1992). A ferramenta imperfeita - língua, sujeito e discurso, tradução de Maria Fausta Pereira de Castro, Campinas: Editora da Unicamp.

LACAN, J. (1979). Os quatro conceitos fundamentais da psicanálise - livro XI, tradução de M. D. Magno, Rio de Janeiro: Zahar Editores.

(1992). O avesso da psicanálise - livro XVII - versão brasileira de Ari Roitman, Rio de Janeiro: Jorge Zahae Editor.

MILNER, J.-C. (1996). A obra clara - Lacan, a ciência, a filosofia, tradução de Procópio Abreu, Rio de Janeiro: Jorge Zahar Editor.

PORGE, E. (2000). Jacques Lacan, un psychanalyste - parcours d'un enseignement, Ramonville Saint-AGNE: Editions Érès. 